\title{
Glucose-limiting conditions induce an invasive population of MDA-MB-231 breast cancer cells with increased connexin 43 expression and membrane localization
}

\author{
Jennifer C. Jones ${ }^{1,8} \cdot$ Amanda M. Miceli $^{2} \cdot$ Mary M. Chaudhry $^{3} \cdot$ Chloe S. Kaunitz $^{4} \cdot$ Mallika A. Jai $^{3}$. \\ Romel N. Pancho ${ }^{3}$. Alan Lazzar ${ }^{3}$ - Bradley S. Taylor ${ }^{3}$. Vishnupriya Bodempudi ${ }^{3}$. Prarthana P. Jain ${ }^{4}$. Sheeri Hanjra ${ }^{3}$. \\ Alexander E. Urban ${ }^{4} \cdot$ Brian Zanotti $^{5} \cdot$ Ellen K. Kohlmeir $^{6} \cdot$ Thomas M. Bodenstine $^{1,2,7,8}$
}

Received: 18 December 2019 / Accepted: 9 December 2020 / Published online: 16 February 2021

(c) The Author(s) 2021

\begin{abstract}
Gap junctional intercellular communication (GJIC) is a homeostatic process mediated by membrane channels composed of a protein family known as connexins. Alterations to channel activity can modulate suppression or facilitation of cancer progression. These varying roles are influenced by the cancer cell genetic profile and the context-dependent mechanisms of a dynamic extracellular environment that encompasses fluctuations to nutrient availability. To better explore the effects of altered cellular metabolism on GJIC in breast cancer, we generated a derivative of the triple-negative breast cancer cell line MDA-MB-231 optimized for growth in low-glucose. Reduced availability of glucose is commonly encountered during tumor development and leads to metabolic reprogramming in cancer cells. MDA-MB-231 low-glucose adapted cells exhibited a larger size with improved cell-cell contact and upregulation of cadherin-11. Additionally, increased protein levels of connexin 43 and greater plasma membrane localization were observed with a corresponding improvement in GJIC activity compared to the parental cell line. Since GJIC has been shown to affect cellular invasion in multiple cancer cell types, we evaluated the invasive qualities of these cells using multiple three-dimensional Matrigel growth models. Results of these experiments demonstrated a significantly more invasive phenotype. Moreover, a decrease in invasion was noted when GJIC was inhibited. Our results indicate a potential response of triple-negative breast cancer cells to reduced glucose availability that results in changes to GJIC and invasiveness. Delineation of this relationship may help elucidate mechanisms by which altered cancer cell metabolism affects GJIC and how cancer cells respond to nutrient availability in this regard.
\end{abstract}

Keywords Connexin · Gap junction · Breast cancer

\author{
Abbreviations \\ C $\times 43$ Connexin 43 \\ GJIC Gap junctional intercellular communication
}

Thomas M. Bodenstine

tboden@midwestern.edu

1 Department of Biochemistry and Molecular Genetics, Midwestern University, 555 31st Street, Downers Grove, IL 60515, USA

2 Chicago College of Pharmacy, Midwestern University, 555 31st Street, Downers Grove, IL 60515, USA

3 Biomedical Sciences Program, Midwestern University, 555 31st Street, Downers Grove, IL 60515, USA

4 Chicago College of Osteopathic Medicine, Midwestern University, 555 31st Street, Downers Grove, IL 60515, USA
5 Department of Microbiology and Immunology, Midwestern University, 555 31st Street, Downers Grove, IL 60515, USA

6 Core Facilities, Midwestern University, 555 31st Street, Downers Grove, IL 60515, USA

7 College of Health Sciences, Midwestern University, 555 31st Street, Downers Grove, IL 60515, USA

8 College of Graduate Studies, Midwestern University, 555 31st Street, Downers Grove, IL 60515, USA 


\section{Introduction}

The development and progression of cancer is affected by genetic alterations within cancer cells and an everchanging microenvironment that influences their behavior. Limitations in nutrient availability are common during tumor growth in hypoxic regions of primary tumors and colonization at metastatic sites as cancer cells encounter new tissue microenvironments (Simoes et al. 2015; DeBerardinis and Chandel 2016). In particular, heterogenous blood perfusion within tumors leads to decreased oxygen and glucose levels and a reprogramming of cellular signaling which creates new cellular phenotypes optimized for growth in these conditions (Vaupel et al. 1989; Gillies et al. 1999; Garcia-Jimenez and Goding 2019). The ability of cancer cells to adapt to these changing conditions increases their potential to survive and proliferate. This often requires utilization of secondary fuel sources for nitrogen and carbon and necessitates modifications to biochemical pathways (DeBerardinis and Chandel 2016; Pavlova and Thompson 2016).

Gap junctions are intercellular channels mediated by a family of proteins known as connexins and support cellular homeostasis by allowing the regulated passage of ions, nutrients and signaling molecules (Nielsen et al. 2012). This gap junctional intercellular communication (GJIC) is often dysregulated in cancer where it is frequently decreased due to downregulation of connexin genes, mislocalization of connexin proteins and changes to cellular adhesion junctions (Aasen et al. 2016). Numerous reports have demonstrated a causative relationship between the loss of GJIC and acquisition of cancer cell hallmarks or suppression of these features following restoration of GJIC (Mehta et al. 1991; King and Lampe 2004; Shao et al. 2005; Wang et al. 2014). However, other data have established that GJIC can also promote aggressive qualities in cancer cells (Bates et al. 2007; Ghosh et al. 2014; Hong et al. 2015; Zibara et al. 2015). Multiple models have demonstrated connexin expression and/or GJIC to be correlated with metastasis (Lamiche et al. 2012; Ogawa et al. 2012; Tang et al. 2013). Moreover, cancer cell gap junctions form between endothelial cells during metastasis, as well as stromal cells at secondary metastatic sites (el-Sabban and Pauli 1994; Chen et al. 2016). Thus, GJIC remains a dynamic process in the cancer cell, consequences of which are influenced by context-dependent mechanisms that may suppress or promote cancer cell survival and function.

An increased understanding of the role GJIC plays in cancer cell metabolism is providing important information for how gap junctions mediate the transfer of metabolites in the tumor microenvironment (Contreras et al.
2002; Dovmark et al. 2017, 2018). Conversely, to better understand the role of metabolism in regulation of GJIC, we evaluated changes in the triple-negative breast cancer cell line MDA-MB-231 when these cells adapted to low-glucose availability, a variant we refer to as MDAMB-231 ${ }^{\mathrm{LG}}$. This derivative exhibited increased connexin protein expression and GJIC. Additionally, these cells exhibited highly invasive qualities that were affected, in part, by inhibition of GJIC.

\section{Materials and methods}

\section{Antibodies}

Antibodies targeting connexin 43, actin, vimentin, N-cadherin, E-cadherin, claudin-1, cadherin-11 (immunofluorescence), $\beta$-catenin, LC3 and horse radish peroxidase conjugated secondary antibodies were purchased from Cell Signaling (Danvers, MA, USA). Cadherin-11 antibody (western blot) and Alexa fluor conjugated secondary antibodies for immunofluorescence were purchased from Thermo Fisher Scientific (Waltham, MA, USA). GAPDH antibody was purchased from EMD Millipore. HIF1 $\alpha$ antibody was purchased from BD Biosciences.

\section{Cell lines and culture}

MDA-MB-231 (HTB-26), Hs578T (HTB-126), MCF-7 (HTB-22) and T47D (HTB-133) cell lines were purchased from the American Type Culture Collection (ATCC; Manassas, VA, USA) and maintained in RPMI 1640 supplemented with $10 \%$ fetal bovine serum (FBS). Cells were grown in a humidified incubator at $37{ }^{\circ} \mathrm{C}, 5 \% \mathrm{CO}_{2}$ and passaged using trypsin-EDTA. Routine screening for mycoplasma was performed via PCR detection using the Promokine PCR Mycoplasma Test Kit I/C (PromoCell, Heidelberg, Germany). MDA-MB-231 ${ }^{\mathrm{LG}}$ were grown in RPMI 1640 glucose-free media supplemented with $10 \%$ FBS. All experiments involving parental and LG cells were performed in the respective media unless otherwise indicated. All cells were validated by short tandem repeat (STR)-analysis at the Northwestern University NUSeq Core Facility (Chicago, IL, USA) and compared to ATCC cell identification data for verification (Table 1, Supp. Table 1).

\section{Proliferation and viability}

Cellular proliferation and viability were measured by use of CellTiter 96 AQueous One Solution reagent (EMD Millipore) on a PerkinElmer Enspire Multimode plate reader (Waltham, MA, USA) according to manufacturer's protocols. CellEvent Green Caspase 3/7 and SYTOX-AADvanced 
Table 1 STR analysis of MDA-MB-231 and MDA-MB-231 ${ }^{\mathrm{LG}}$

\begin{tabular}{lll}
\hline Marker & MDA-MB-231 & MDA-MDB-231 \\
\hline Amelogenin* & $\mathrm{X}$ & $\mathrm{X}$ \\
D3S1358 & 16 & 16 \\
D1S1656 & 15,17 & 15,17 \\
D2S441 & 14,15 & 14,15 \\
D10S1248 & 14,16 & 14,16 \\
D13S317* & 13 & 13 \\
Penta E & 11 & 11 \\
D16S539* & 12 & 12 \\
D18S51 & 11,16 & 11 \\
D2S1338 & 20,21 & 20,21 \\
CSF1PO* & 12,13 & 12,13 \\
Penta D & 11,14 & 11,14 \\
TH01* & $7,9.3$ & $7,9.3$ \\
vWA* & 15,18 & 15,18 \\
D21S11 & $30,33.2$ & $30,33.2$ \\
D7S820* & 8,9 & 8,9 \\
D5S818* & 12 & 12 \\
TPOX* & 8,9 & 8,9 \\
D8S1179 & 13 & 13 \\
D12S391 & 17,18 & 17,18 \\
D19S433 & 11,14 & 11,14 \\
FGA & 22,23 & 22,23 \\
D22S1045 & 16 & 16 \\
\hline Astisk & & 13
\end{tabular}

Asterisk indicate 9 markers defined by ATCC criteria for $100 \%$ match

reagents (Invitrogen, Carlsbad, CA, USA) were used to assess caspase activity and cell integrity using a Beckman Coulter (Brea, CA, USA) CytoFLEX flow cytometer with CytExpert analysis software. Positive controls for CellEvent reagent were demonstrated with staurosporine (Caspase 3/7) and heat killing (SYTOX) (Supp. Fig. 1).

\section{pH readings}

Cells were plated at equal densities and allowed to grow for $96 \mathrm{~h}$ without media changes. At $96 \mathrm{~h}$ media from wells was removed and filtered through a $0.22 \mu \mathrm{m}$ sterile filter and read on a Mettler-Toledo SevenEasy $\mathrm{pH}$ meter.

\section{Scanning electron microscopy}

Cells were grown on glass coverslips and fixed with $4 \%$ paraformaldehyde at $4{ }^{\circ} \mathrm{C}$ for $24 \mathrm{~h}$. Cells were then washed with phosphate-buffered saline (PBS), dehydrated with increasing concentrations of ethanol $(30 \%, 50 \%, 70 \%, 80 \%, 95 \%$ and $100 \%$ for $10 \mathrm{~min}$ each at $4{ }^{\circ} \mathrm{C}$ ), and dried in a Leica (Wetzlar, Germany) EM CPD300 critical point dryer. Samples were then sputter-coated with $10 \mathrm{~nm}$ silver using a Leica EM ACE600. Cells were visualized with a JEOL (Akishima,
Tokyo, Japan) JCM-6000Plus scanning electron microscope at $5 \mathrm{kV}$ and $10 \mathrm{kV}$.

\section{Fluorescence microscopy and GJIC analysis}

For immunofluorescence, cells were grown on glass coverslips in 24-well plates, washed with ice cold PBS and fixed in ice cold $100 \%$ methanol at $-20^{\circ} \mathrm{C}$ for $20 \mathrm{~min}$. Cells were blocked in 2\% bovine serum albumin (BSA) in PBS and incubated with indicated antibodies. For GJIC analysis, cells were analyzed by the method of Goldberg and quantified by flow cytometry (Goldberg et al. 1995; Czyz et al. 2000). Briefly, donor cells were labeled with $5 \mu \mathrm{M}$ of the lipophilic permanent dye CM-DiI (Invitrogen) and $10 \mu \mathrm{M}$ calcein-AM (Invitrogen) and cultured with non-labeled cells. Spread of calcein from donor cells (CM-DiI/calcein positive) to acceptor cells (calcein only) indicated GJIC activity as demonstrated with the highly gap junction coupled Hs578T breast cancer cell line (Supp. Fig. 2a). Images for immunofluorescence and GJIC analysis were obtained with a Leica DMi8 fluorescent microscope equipped with a Leica DFC 9000GT camera and X-Cite XLED1 fluorescence source (Lumen Dynamics, Mississauga, Ontario, Canada). Quantification of GJIC was performed using a BD Biosciences (San Jose, CA, USA) FACSCalibur flow cytometer with CellQuest Pro software using the assay described above with $0.5 \mu \mathrm{M}$ Cell Tracker Deep Red (Invitrogen) and $0.75 \mu \mathrm{M}$ calcein-AM (Supp. Fig. 2b). Coupling efficiency was represented as the level of GJIC activity and calculated as acceptor cells/donor cells and normalized to control.

\section{Matrigel invasion assays}

Growth factor reduced (GFR) Matrigel basement membrane matrix (Corning, NY, USA) was utilized for two different three-dimensional cell culture assays. For the embedded assay, Matrigel was diluted from 8 to $5 \mathrm{mg} / \mathrm{ml}$ using RPMI 1640 with or without glucose with $10 \%$ FBS before $300 \mu \mathrm{l}$ was added to each well. $30 \mu \mathrm{l}$ of $1 \times 10^{6}$ cells $/ \mathrm{ml}$ were added to $270 \mu \mathrm{l}$ of diluted Matrigel and added on top of the first layer. After approximately 30-45 min of incubation, $500 \mu \mathrm{l}$ of appropriate medium was added to the Matrigel layers. For the on-top assay, $300 \mu 1$ of Matrigel was added directly to the wells without dilution. The Matrigel layer was allowed to solidify at $37{ }^{\circ} \mathrm{C}$ and $5 \% \mathrm{CO}_{2}$ for $45 \mathrm{~min}$ and $250 \mu \mathrm{l}$ of 25,000 cells $/ \mathrm{ml}$ were plated directly on top of the first Matrigel layer and allowed to incubate for $45 \mathrm{~min} .25 \mu \mathrm{l}$ of Matrigel was mixed with $225 \mu \mathrm{l}$ of the appropriate medium and added to the wells. Cells were then incubated for 6 days for each assay with medium changed at $48 \mathrm{~h}$.

Growth factor reduced Matrigel invasion chambers (Corning) were used for the Matrigel invasion assay. $500 \mu \mathrm{l}$ of warm serum-free medium ( $\pm 2 \mathrm{mM}$ glucose) was added to 
each transwell insert for $2 \mathrm{~h}$ in the incubator to rehydrate the Matrigel. Cell suspensions were made at a concentration of 100,000 cells/well in serum-free medium. Medium in inserts was removed after $2 \mathrm{~h}$ before cell suspensions were added to each insert. $750 \mu \mathrm{l}$ of $5 \%$ FBS medium was added as a chemoattractant to the bottom of wells in the 24-well plate. The invasion assay was incubated for a total of $24 \mathrm{~h}$. A sterile cotton swab was used to remove non-invasive cells from the membrane. Pre-chilled $100 \%$ methanol was used as a fixative at $500 \mu \mathrm{l}$ per insert for approximately $20 \mathrm{~min}$ on an orbital shaker at $4{ }^{\circ} \mathrm{C}$. Invading cells were stained with crystal violet or mounted to glass slides using Fluoroshield with DAPI (Thermo Fisher Scientific) for quantification and imaged using a Nikon (Minato, Tokyo, Japan) Eclipse Ti2 microscope with Fi3 camera. Quantification of DAPI was performed using NIS Elements AR software.

\section{Western blot analysis}

Whole cell lysates were collected using lysis buffer containing $25 \mathrm{mM}$ Tris, pH 7.4, 5\% glycerol, $1 \%$ SDS and $1 \times$ protease and phosphatase inhibitors (Thermo Fisher Scientific). Lysates were passaged through a 21-gauge needle $10 \times$ on ice, combined with Laemmli sample buffer supplemented with $\beta$-mercaptoethanol and heated at $95{ }^{\circ} \mathrm{C}$ for $10 \mathrm{~min}$. Samples were separated using $12 \%$ SDS-PAGE, transferred to PVDF and detected by enhanced chemiluminescence using a Bio-Rad Gel Imager (Hercules, CA, USA). Blocking and antibody solution consisted of 5\% non-fat dry milk in tris-buffered saline with $0.1 \%$ tween-20. HEK293T connexin 43 overexpression lysate and empty vector control were purchased from Novus Biologicals. Additional cell lines were used as positive controls for some proteins and analyzed under the same conditions listed above. Hs578T, N-cadherin (Hazan et al. 1997; Nieman et al. 1999); MCF7, E-cadherin (Nieman et al. 1999; Pishvaian et al. 1999); T47D, claudin-1 (Majer et al. 2016; Mattern et al. 2019). Densitometry was performed using NIH ImageJ software and proteins of interest normalized to actin.

\section{Statistical analysis}

Analysis was performed using GraphPad Prism 8. Data are presented as mean \pm standard deviation (SD) and significance determined using unpaired student $t$ test analysis. Differences were considered statistically significant at $p<0.05(*)$.

\section{Results}

\section{Characterization of MDA-MB-231 ${ }^{\text {LG }}$}

To examine the effects of metabolic changes on GJIC in breast cancer cells, we grew the MDA-MB-231 cell line in RPMI 1640 without glucose and supplemented with $10 \%$ FBS. Because trace amounts of glucose are present within FBS, we did not consider this media glucose-free. However, based on manufacturer's specifications, final glucose concentration in the prepared media were below $0.130 \mathrm{mM}$. This accounted for a greater than $15 \times$ fold reduction in available glucose compared to control RPMI 1640 containing $2 \mathrm{mM}$ glucose. Growth in this media decreased viability within 2-4 days of culture when evaluated using an MTT assay (Fig. 1a). To generate a population of cells optimized for growth in these conditions, we plated MDA-MB-231 at low density (20-30\% confluence) and maintained surviving cells for 4-6 weeks. Media was replaced every 2 days to remove apoptotic cells and cellular debris. Small populations of surviving cells initially exhibited quiescence followed by restoration of cellular proliferation. To avoid clonal selection, surviving populations from multiple plates were combined and propagated. The growth pattern of these cells normalized and regular maintenance was initiated using continued culture in low-glucose media. The surviving population exhibited morphology that was noticeably different from the parental MDA-MB-231 (Fig. 1b). Cells were larger with rounded membranes, distinctly different from the mesenchymal morphology of the parental MDA-MB-231. These cells were designated MDA-MB- $231^{\mathrm{LG}}$ for their ability to grow in low glucose conditions. MDA-MB-231 ${ }^{\mathrm{LG}}$ did not acidify low-glucose culture media compared to parental cells grown under standard conditions as evidenced by the effects on phenol-red (Fig. 1c). Analysis of cellular proliferation showed a similar growth pattern (Fig. 1d). Cells appeared healthy with minimal signs of cellular stress. To confirm this, we assessed markers for apoptosis (caspase-3/7 cleavage) and overall cellular integrity (SYTOX) by flow cytometry demonstrating greater than $90 \%$ viability in low-glucose media similar to that of MDA-MB-231 grown in control media (Fig. 1e). As our growth conditions involved the reduction of glucose but did not affect oxygenation, we evaluated levels of LC3II as a marker of autophagy and hypoxia inducible factor $\alpha$ (HIF $1 \alpha$ ) as an indicator of response to hypoxic conditions. Indeed, greater levels of LC3II were present in the MDAMB- $231^{\text {LG }}$ while HIF $1 \alpha$ remained relatively unchanged (Fig. 1f).

Since the MDA-MB-231 ${ }^{\mathrm{LG}}$ displayed considerably different morphology, we verified that the MDA-MB-231 ${ }^{\mathrm{LG}}$ were a true derivative of the parental MDA-MB-231. STRanalysis was performed to validate each cell line. Both the MDA-MB-231 and MDA-MB-231 ${ }^{\mathrm{LG}}$ resulted in a 9/9 match for markers established by ATCC to confirm identity of cell lines corresponding to a $100 \%$ match by these criteria (Table 1). An additional 14 markers were also examined and demonstrated $>96 \%$ similarity with 


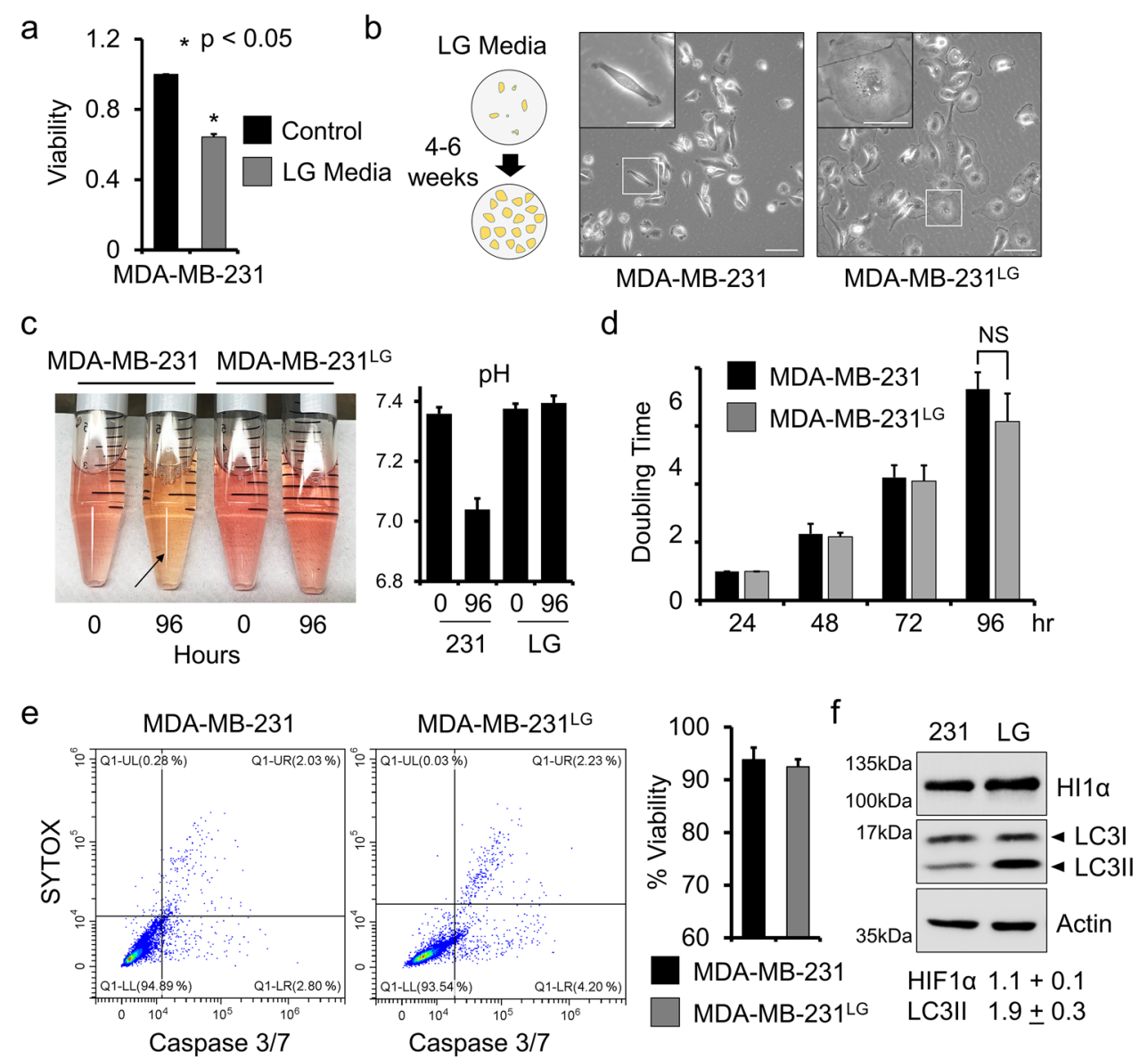

Fig. 1 Characterization of MDA-MB-231 ${ }^{\mathrm{LG}}$. a MTT assay demonstrating viability of MDA-MB-231 cells grown in control or lowglucose (LG) media for $72 \mathrm{~h}$. Experiments were performed in triplicate three independent times. Results were normalized to control and represented as fold change. Data represent the mean \pm SD. $\left({ }^{*} p<0.05\right)$ b Phase microscopy of MDA-MB-231 and MDA-MB-231 ${ }^{\mathrm{LG}} \mathrm{dem}-$ onstrating differences in morphology and size. Scale bar: $100 \mu \mathrm{m}$; inset: $50 \mu \mathrm{m}$. c Cell lines were grown in respective media (control, LG) for $96 \mathrm{~h}$. Time 0 represents unused media at start of experiment. Arrow indicates acidification based on color of phenol-red in culture media. Quantification readings were performed in triplicate and data represent the mean of three independent experiments \pm SD. d Doubling-times for each cell line at 48, 72 and $96 \mathrm{~h}$. Experiments

the only difference at marker D18S51 corresponding to a heterozygous versus homozygous result in parental MDAMB-231 and MDA-MB-231 ${ }^{\mathrm{LG}}$ respectively.

\section{Increased membrane contact in MDA-MB-231 ${ }^{\mathrm{LG}}$}

When observed by phase microscopy, MDA-MB-231 ${ }^{\mathrm{LG}}$ appeared to exhibit greater contact at the plasma membrane between cells. To examine this in more detail, we performed scanning electron microscopy of both the MDA-MB-231 were performed in triplicate and represent the mean of three independent experiments \pm SD. (NS, not significant) e Evaluation of cellular viability by flow cytometry using markers for cleavage of caspase-3 (x-axis) to indicate apoptosis and SYTOX (y-axis) as a marker of cellular integrity/necrosis. Data was quantified and presented as $\%$ viability. Experiments were performed in triplicate and data represent the mean of two independent experiments \pm SD. $\mathbf{f}$ Representative western blot analysis of three independent experiments for HIF1 $\alpha$ and LC3. Densitometry represents fold-change \pm SD in MDA-MB- $231^{\mathrm{LG}}$ compared to MDA-MB-231. $\beta$-actin used as a loading control. b-f MDA-MB-231 cultured in control media; MDA-MB-231 ${ }^{\text {LG }}$ cultured in low-glucose media

and MDA-MB-231 ${ }^{\mathrm{LG}}$. Results demonstrated an expected mesenchymal phenotype in MDA-MB-231 showing an elongated appearance with overlapping membranes and minimal cell-cell junctions (Fig. 2a). In contrast, MDA-MB-231 ${ }^{\mathrm{LG}}$ clearly showed an increased ability to form cell-cell junctions with non-overlapping membrane connections along portions of their plasma membranes (Fig. 2a, b). While both cell lines exhibited lamellipodia and filopodia, long pseudopodia were noted in the MDA-MB-231 ${ }^{\mathrm{LG}}$ (Fig. 2a). High 
Fig. 2 MDA-MB-231 ${ }^{\mathrm{LG}}$ exhibit increased membrane contact. a Analysis of MDA-MB-231 and MDA-MB-231 ${ }^{\text {LG }}$ morphology and cell-cell interactions by scanning electron microscopy at indicated magnifications. *Indicates overlapping membranes; arrows indicate sites of cell-cell membrane contact. L: lamellipodia; F: filopodia; P: pseudopodia $\mathbf{b}$, High magnification images of membrane interactions in MDA-MB-231 $1^{\mathrm{LG}}$ a
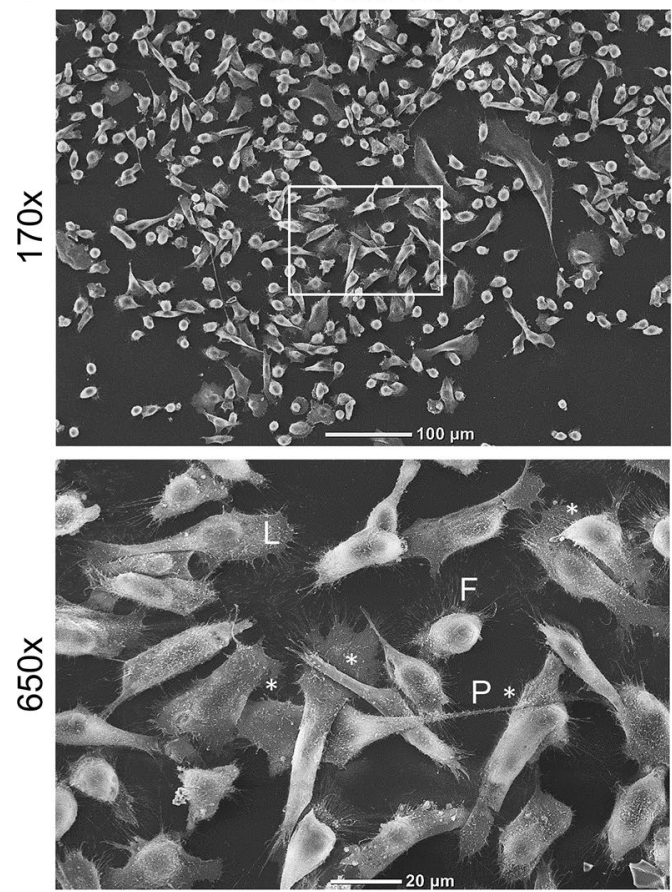

b

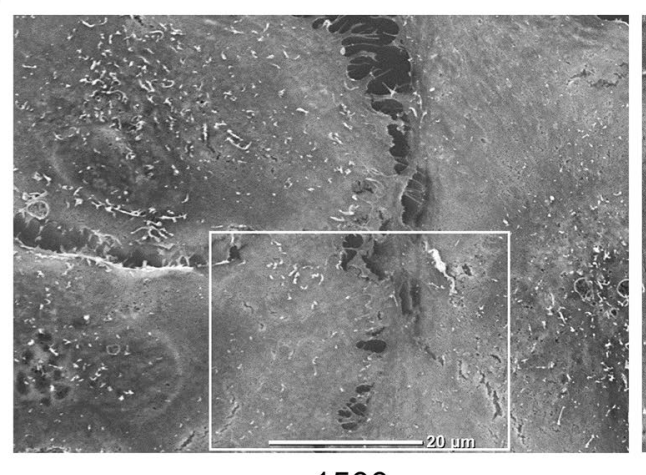

$1500 x$
MDA-MB-231 LG
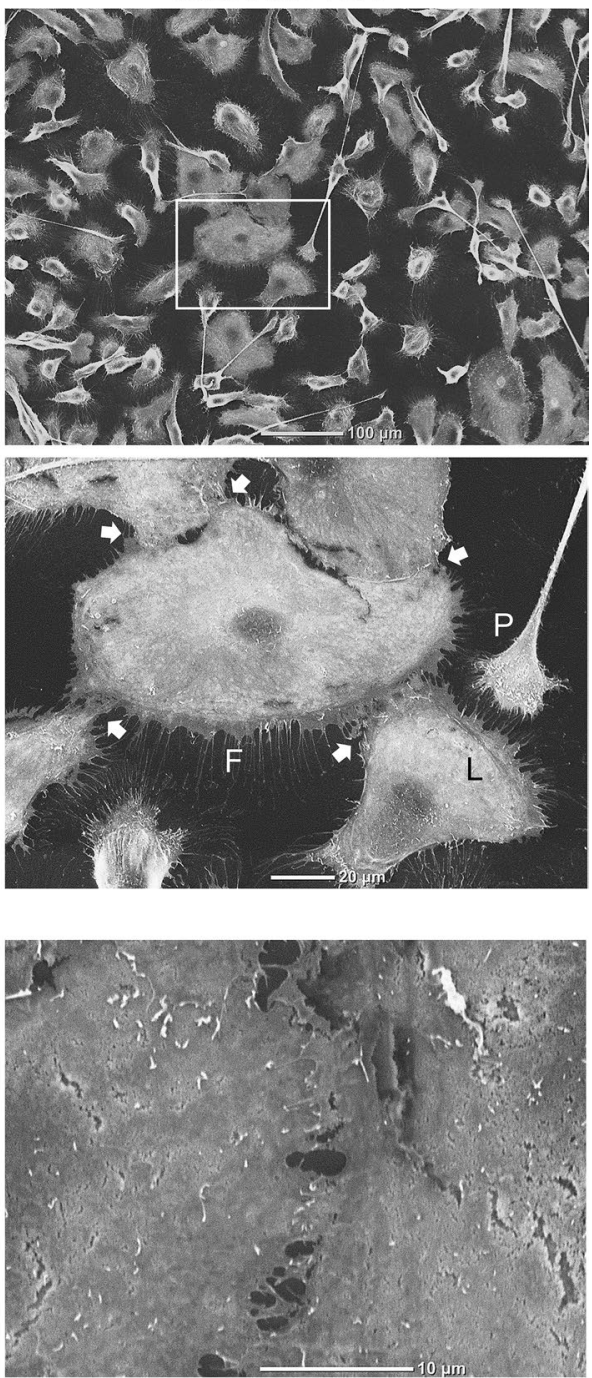

$3000 x$

MDA-MB-231LG

power analysis allowed for the observation of membrane contact between MDA-MB-231 ${ }^{\mathrm{LG}}$ cells (Fig. 2b).

Due to these observations, we examined markers of epithelial-to-mesenchymal transition (EMT) to determine if re-expression of epithelial markers may account for the increased cell-cell junctions. Epithelial-cadherin (E-cadherin, $C D H 1)$ and claudin-1 (CLDNI) were not detected in either MDA-MB-231 or MDA-MB-231 ${ }^{\mathrm{LG}}$ (Fig. 3a), indicating that upregulation of these markers was not responsible for the increased cell-cell attachment noted in the MDA-MB-231 ${ }^{\mathrm{LG}}$. N-cadherin ( $\left.\mathrm{CDH} 2\right)$, a mesenchymalassociated cadherin was not detected in the MDA-MB-231 or the MDA-MB-231 ${ }^{\mathrm{LG}}$ and levels of the intermediate filament and mesenchymal marker vimentin (VIM) remained relatively unchanged (Fig. 3a). However, MDA-MB-231 have been shown to express cadherin-11 (CDH11) and analysis in the MDA-MB-231 ${ }^{\mathrm{LG}}$ demonstrated a significant increase in the levels of this attachment factor (Fig. 3a). When observed by immunofluorescence, strong membrane localization was observed throughout the cell population, particularly at sites of cell-cell contact (Fig. 3b). By comparison, cadherin-11 was observed intermittently throughout MDA-MB-231 populations. Levels of $\beta$-catenin (CTNNB1), a multi-function protein involved in both cellular signaling and cell-cell attachment, remained similar between the cell lines (Fig. 3a). However, increased fluorescence overlap of $\beta$-catenin with cadherin-11 at the plasma membrane was apparent in the MDA-MB-231 $1^{\mathrm{LG}}$ (Fig. 3b). 
Fig. 3 Cadherin-11 protein levels are increased in MDA-MB$231^{\mathrm{LG}}$. a Representative western blot analyses for membrane and cytoskeletal EMT markers. All experiments performed three independent times. Detection of bands in positive control cell lines shown for E-cadherin, $\mathrm{N}$-cadherin and claudin-1. Densitometry represents foldchange \pm SD for vimentin, $\beta$-catenin and cadherin-11 in MDA-MB-231 ${ }^{\text {LG }}$ compared to MDA-MB-231. $\beta$-actin used a loading control. b Representative immunofluorescence analysis of three independent experiments examining $\beta$-catenin and cadherin-11. Merged images demonstrate fluorescence overlap. DAPI, blue; $\beta$-catenin, green; cadherin-11, red. Scale bar: $20 \mu \mathrm{m}$; inset: $10 \mu \mathrm{m}$
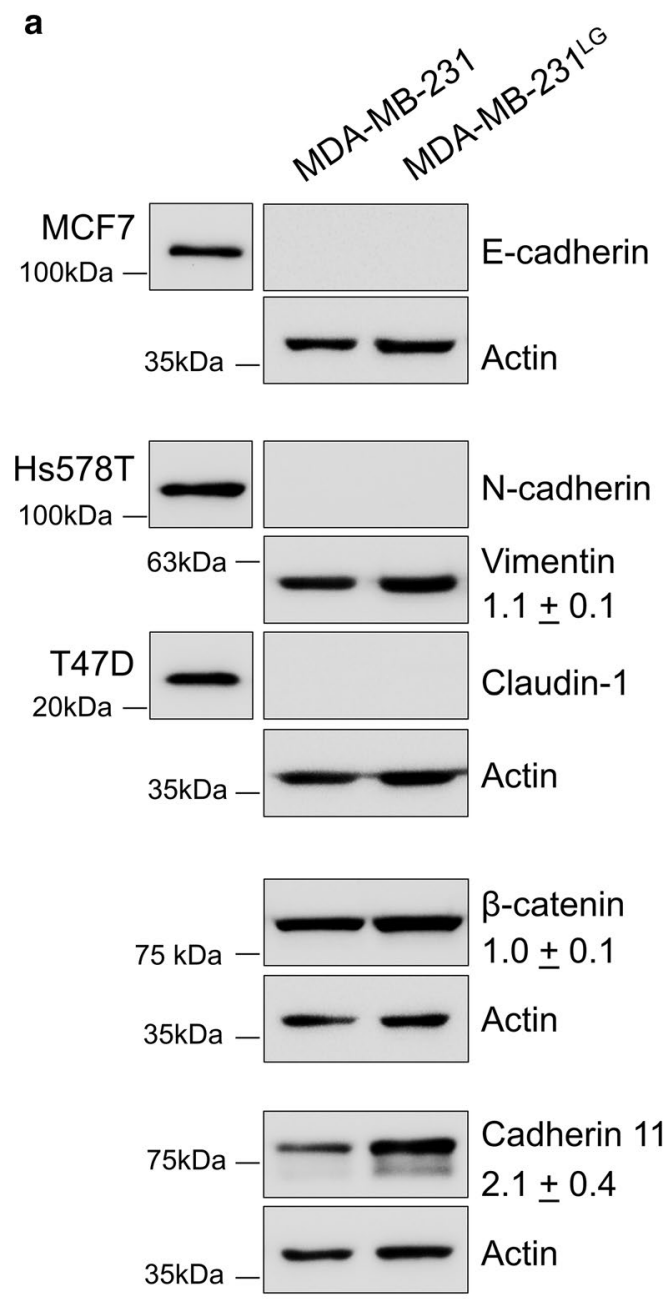

b MDA-MB-231 MDA-MB-231LG
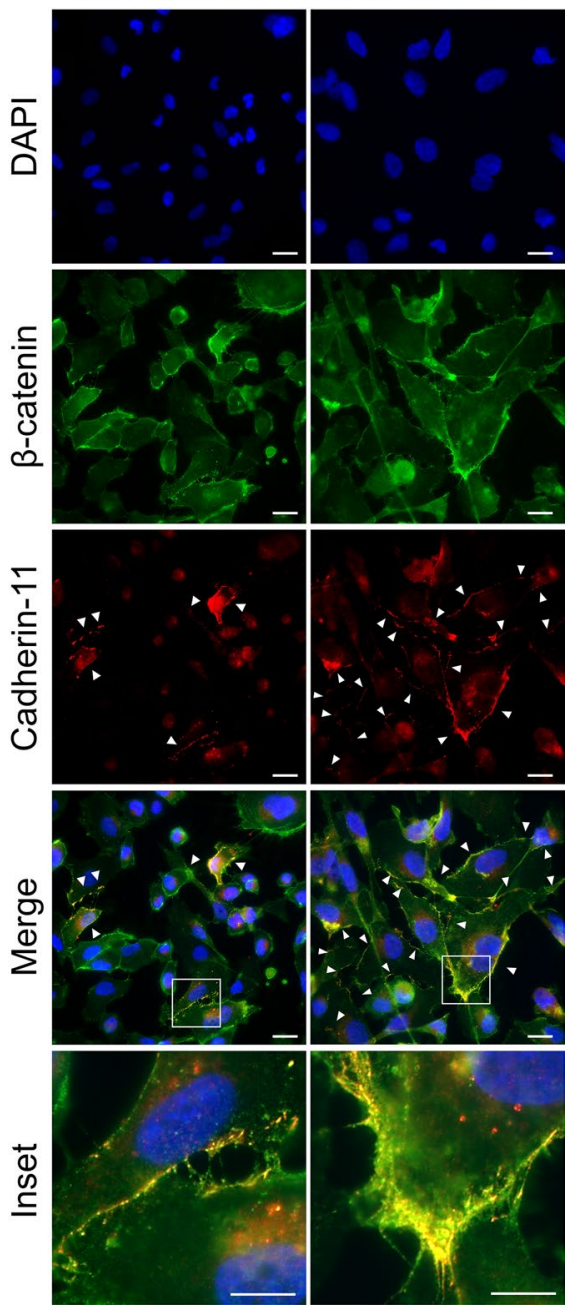

\section{Adaptation to low glucose increases connexin $\mathbf{4 3}$ and GJIC}

We next set out to determine if the metabolic adaptations in the MDA-MB- $231^{\mathrm{LG}}$ and alterations to membrane structure affected GJIC. We first examined protein levels of connexin 43 ( GJA1, $\mathrm{C} \times 43$ ), a major connexin protein expressed in breast tissue and found an increase in proteins levels of this connexin in the MDA-MB-231 ${ }^{\mathrm{LG}}$ (Fig. 4a). $\mathrm{C} \times 43$ is subject to significant post-translational modification and higher molecular weight species of $\mathrm{C} \times 43$ can be detected by western blot analysis (Supp. Fig. 3). However, in both the MDA-MB-231 and MDA-MB-231 ${ }^{\mathrm{LG}}$, we did not detect higher molecular weight species of $\mathrm{C} \times 43$ (Fig. 4a).

We then determined if membrane localization of $\mathrm{C} \times 43$ was also affected in the MDA-MB-231 ${ }^{\mathrm{LG}}$. MDA-MB-231 showed minimal staining for $\mathrm{C} \times 43$ that was predominantly peri-nuclear with little localization at the membrane (Fig. 4b). In contrast, MDA-MB-231 ${ }^{\mathrm{LG}}$ displayed a higher degree of $\mathrm{C} \times 43$ localization at the plasma membrane, particularly at cell junctions, indicative of gap junction formation (Fig. 4b and Supp. Fig. 4). To determine if the increase in $\mathrm{C} \times 43$ membrane localization corresponded to functional gap junctions, a double-label dye transfer technique was performed to assess GJIC with transfer of the fluorescent dye calcein indicating active GJIC. MDA-MB-231 exhibited minimal spread of calcein while a greater number of MDA-MB-231 ${ }^{\mathrm{LG}}$ were capable of transferring this dye to neighboring cells (Fig. 5a). This led to a measurable increase in GJIC when quantitatively assessed by flow cytometry (Fig. 5b).

\section{MDA-MB-231 ${ }^{\mathrm{LG}}$ exhibit increased invasive qualities}

Because changes to GJIC have been shown to affect the invasive capabilities of cancer cells, we sought to evaluate if this quality was also altered in the MDA-MB- $231^{\mathrm{LG}}$. We examined the morphologic appearance of these cells in three-dimensional culture utilizing Matrigel reconstituted basement membrane matrix. Cells were embedded within 
Fig. $4 \mathrm{C} \times 43$ protein levels and membrane localization are increased in MDA-MB-231 ${ }^{\mathrm{LG}}$. a Representative western blot analysis of $\mathrm{C} \times 43$ protein levels from whole cell lysates in three independent experiments. $\beta$-actin used as a loading control. Densitometry represents fold-change $\pm \mathrm{SD}$ for $\mathrm{C} \times 43$ in MDA-MB-231 ${ }^{\mathrm{LG}}$ compared to MDA-MB-231. b Representative immunofluorescence analysis of three independent experiments for $\mathrm{C} \times 43$. DAPI: blue; $\mathrm{C} \times 43$ : green; actin: red. Scale bar: $20 \mu \mathrm{m}$. Additional fields shown in Supp. Figure 4
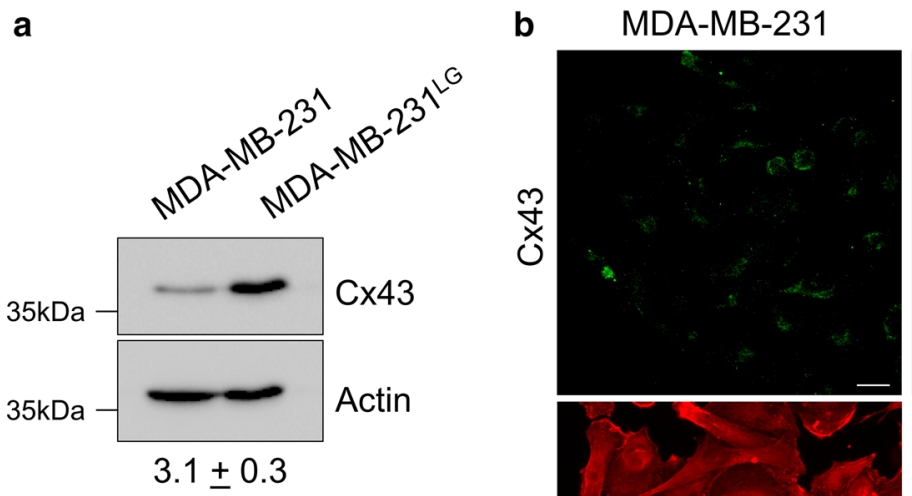

MDA-MB-231LG
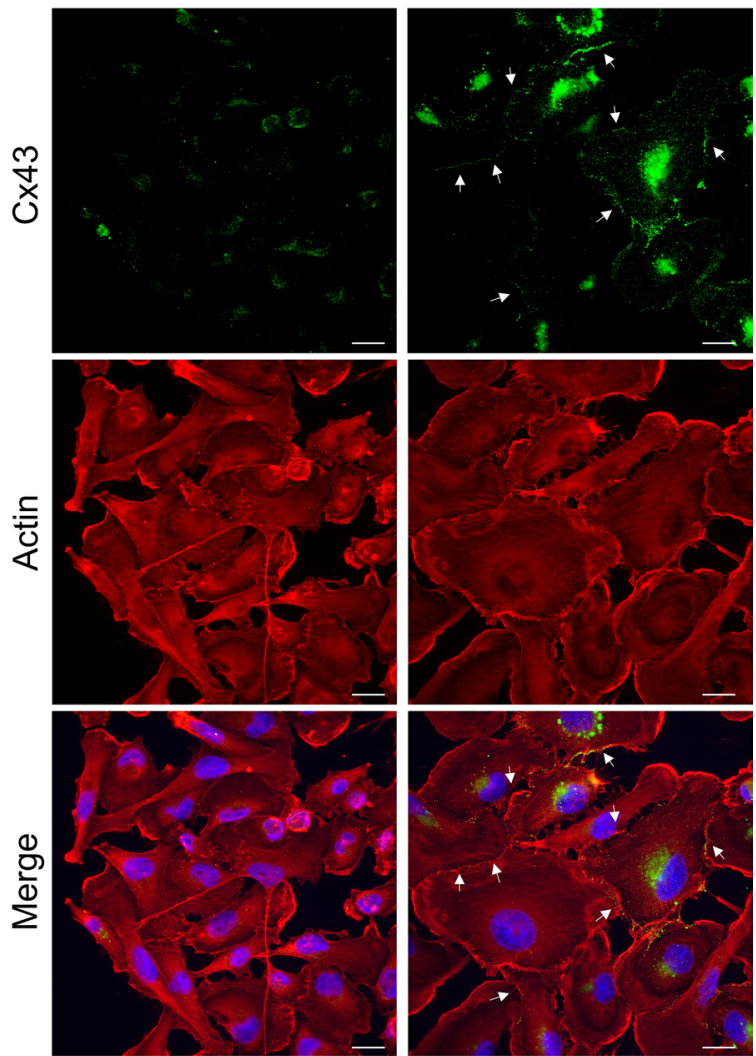

Matrigel, allowing for growth in three-dimension, a condition which more closely resembles cell growth in vivo and allows for observation of phenotypic characteristics. While both MDA-MB-231 and MDA-MB-23 $1^{\mathrm{LG}}$ formed spheroids, MDA-MB-231 ${ }^{\text {LG }}$ exhibited greater stellate extensions at 6 days of culture (Fig. 6a). This was confirmed by use of a second assay in which cells were grown on top of a Matrigel matrix and overlaid with additional Matrigel (Fig. 6b). This procedure allows for more clear documentation of cellular morphologies and extensions and demonstrated a more invasive phenotype in MDA-MB- $231^{\mathrm{LG}}$. To determine if these changes to three-dimensional morphology correlated to increased invasive function, Matrigel invasion chamber assays were used to quantitatively assess the ability of each cell line to invade through a three-dimensional matrix and traverse a membrane containing $8 \mu \mathrm{m}$ pores. Cells were seeded at the top of the matrix in serum-free media and FBS was used as a chemoattractant in the lower chamber of the assay. Invading cells were stained with crystal violet and MDA-MB-231 ${ }^{\mathrm{LG}}$ demonstrated a clear increase in the number of invading cells (Fig. 6c).

To more quantitatively assess the invasive capacity of the MDA-MB-231 ${ }^{\mathrm{LG}}$ we adapted our invasion chamber conditions to fixation with DAPI and analyzed these images using fluorescence microscopy and computer-based software quantification. Additionally, to evaluate potential contributing effects of glucose availability on each cell line, we conducted these experiments in the presence or absence of glucose for $24 \mathrm{~h}$. The MDA-MB-231 ${ }^{\mathrm{LG}}$ exhibited a significantly more invasive capacity in each condition compared to MDA-MB-231 (Fig. 7a, b). The overall results with MDA-MB- $231^{\mathrm{LG}}$ demonstrated significantly higher invasive qualities in each condition.

Finally, to examine a potential link between the increased GJIC in MDA-MB-231 ${ }^{\mathrm{LG}}$ and their invasive qualities, we used the gap junction un-coupling agent $18 \alpha$-glycyrrhetinic acid ( $18 \alpha \mathrm{GA})$ to reduce GJIC in MDA-MB-231 ${ }^{\mathrm{LG}}$. To decrease the possibility of nonspecific effects of $18 \alpha \mathrm{GA}$, we used the minimum concentration of $18 \alpha \mathrm{GA}$ capable of inhibiting GJIC at $24 \mathrm{~h}$ for each condition in the Matrigel invasion chamber assay. This corresponded to $10 \mu \mathrm{M}$ in serum-free conditions (upper chamber) and $50 \mu \mathrm{M}$ in 5\% FBS (lower chamber) (Fig. 8a).18 $\alpha$ GA under these conditions caused a slight but significant reduction in Matrigel chamber invasion of MDA-MB-231 ${ }^{\mathrm{LG}}$ when compared to untreated conditions (Fig. 8b, c). 
Fig. 5 GJIC is increased in MDA-MB- $231^{\mathrm{LG}}$. a Doublelabel fluorescent dye transfer was used to observe GJIC. Transfer of calcein from CMDiI labeled donor cells demonstrates active GJIC. Arrows indicate double-labeled donor cells; asterisk designate calcein positive acceptor cells. Representative fields shown. Calcein: green; CM-DiI: red. Scale bar: $50 \mu \mathrm{m}$. Data represent three independent experiments. b Flow cytometry quantification of coupling efficiency using Cell Tracker Deep Red to mark donor cells and calcein to measure GJIC. Upper right quadrant: double-labeled donor cells; lower left quadrant: non-labeled cells; bottom right quadrant: acceptor cells (calcein only). Experiments were performed in triplicate three independent times. Results were normalized to control and represented as fold change of MDA-MB-231 $1^{\mathrm{LG}}$ compared to MDA-MB-231.

Data represent the mean $\pm \mathrm{SD}$. $(* p<0.05)$ a
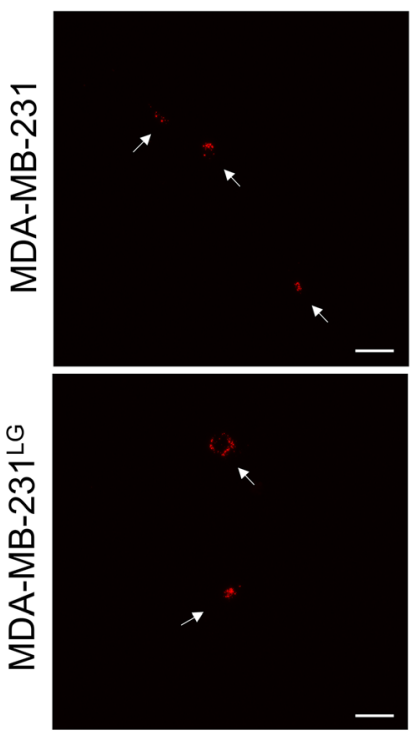

b

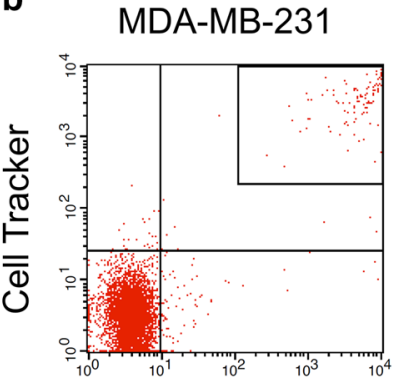

Calcein
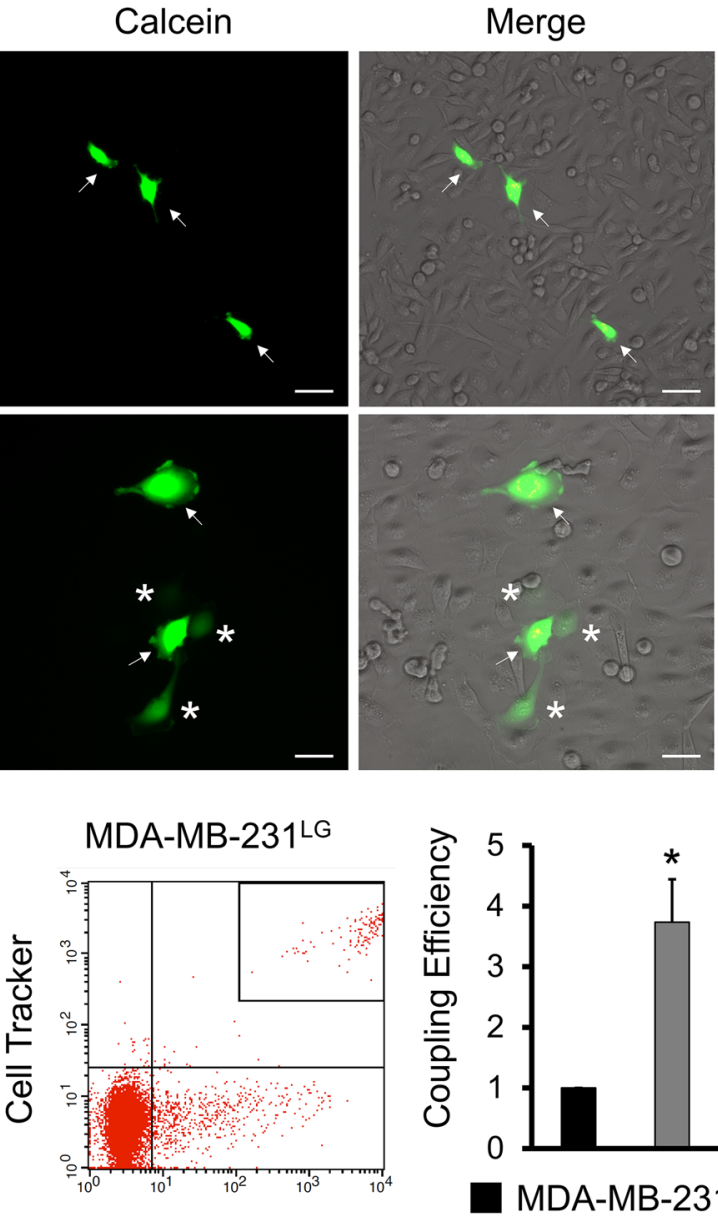

Calcein

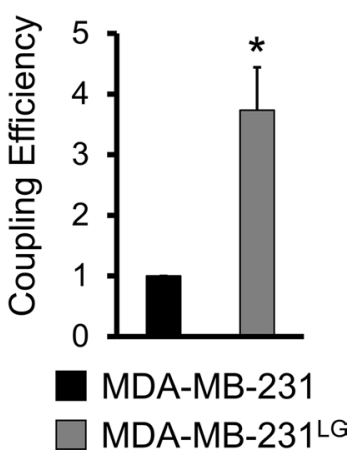

\section{Discussion}

During cancer progression, breast cancer cells exhibit a multitude of responses to the extracellular milieu in which they exist. Among these alterations are changes in GJIC and adaptation to fluctuating metabolic conditions. A better understanding of how these two processes affect each other, and how this contributes to the cancer cell phenotype, will provide important information about this relationship. In this report, we describe the generation of a metabolic variant of the MDA-MB-231 parental cell line adapted for growth in glucose-limiting conditions. These cells maintained a proliferative capacity and high viability despite reduced utilization of this carbon source. The increased levels of autophagy that we observed in the MDA-MB-231 ${ }^{\mathrm{LG}}$ are likely a contributing factor to their survival, yet not high enough to induce autophagic (type II) cell death. We believe that generation of the MDA-MB-231 ${ }^{\mathrm{LG}}$ represent a metabolic adaptation to these growth parameters due to their significantly altered morphology as well as the molecular and functional changes we have characterized. However, persistent subpopulations within the MDA-MB-231 have been reported (Louie et al.
2010; Wang et al. 2015; Amaro et al. 2016; Morata-Tarifa et al. 2016). Therefore, the possibility that the MDA-MB$231^{\mathrm{LG}}$ represent isolation of an existing variant through the selective metabolic pressure described in our experiments remains possible. Although these cells displayed significant differences in appearance and function compared to the parental MDA-MB-231, STR analysis validated these cells a true derivative. Thus, we evaluated the characteristics of the MDA-MB-231 ${ }^{\text {LG }}$ on GJIC and invasion to determine how this metabolic adaptation affected these qualities.

The MDA-MB-231 cell line was originally isolated from a pleural effusion of a patient with an intraductal carcinoma and displayed rounded to spindle-like morphology following establishment in culture (Cailleau et al. 1974). Cells were isolated post-chemotherapeutic treatment and displayed significant aneuploidy. Molecular characterization has revealed a triple-negative profile with mutations in numerous genes including TP53, BRAF and KRAS (Hollestelle et al. 2010). The MDA-MB-231 exhibit a phenotype consistent with EMT and express mesenchymal markers such as the intermediate filament vimentin and lack of epithelial proteins such as E-cadherin (Nieman et al. 1999; Pishvaian et al. 1999; Li 
a

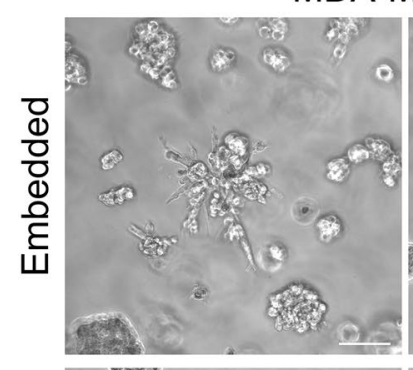

b

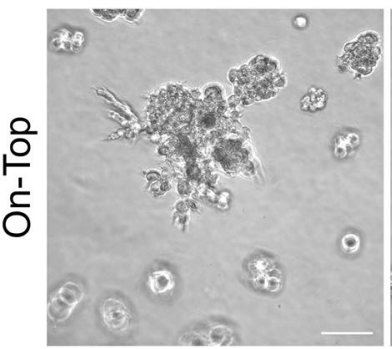

c
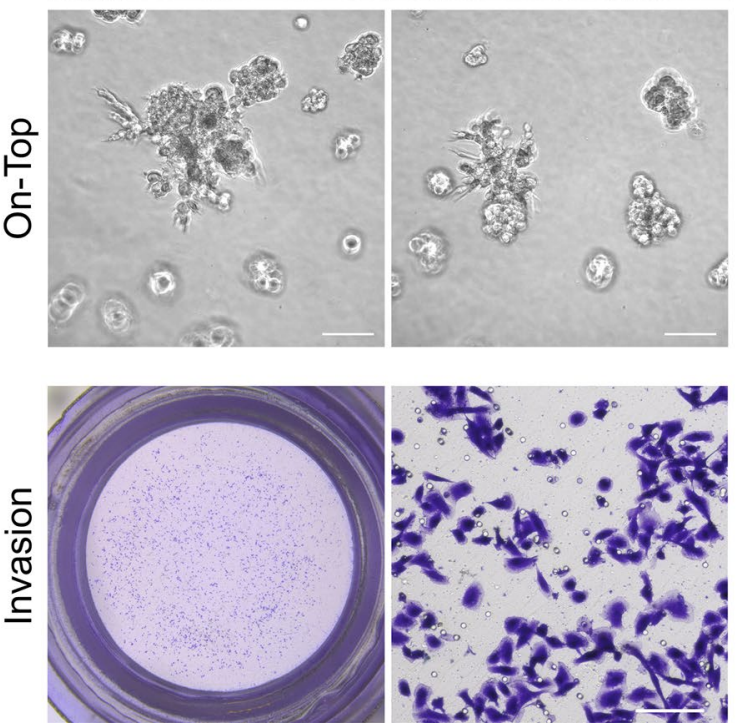

MDA-MB-231LG
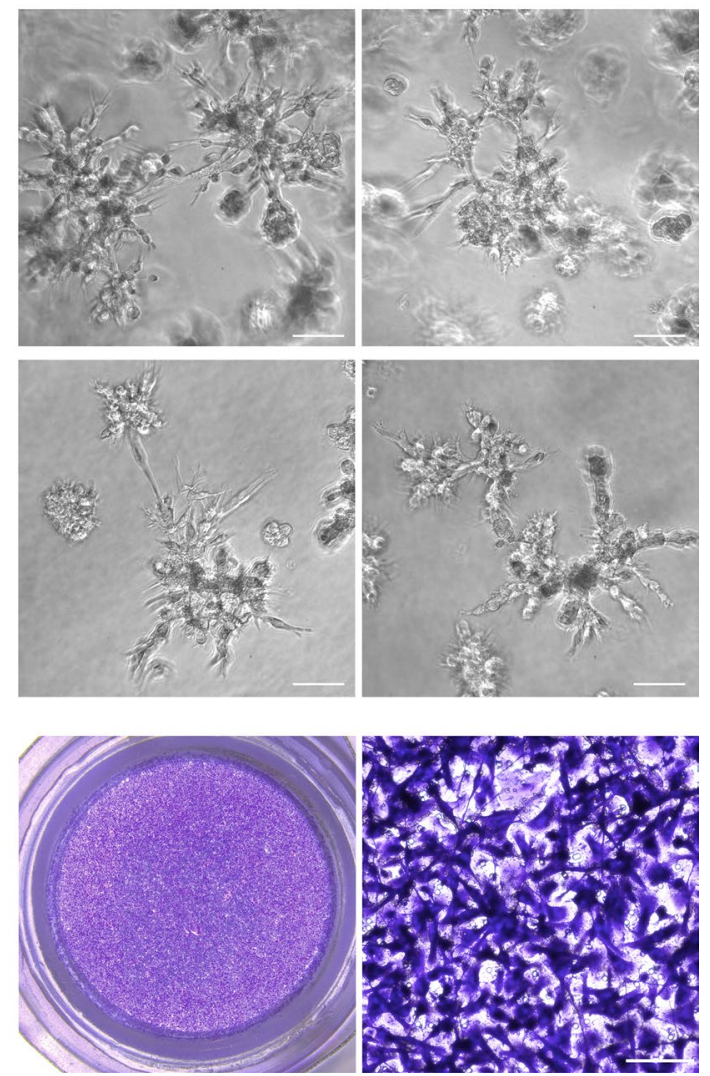

Fig. 6 MDA-MB-231 $1^{\mathrm{LG}}$ display greater invasive qualities. a MDAMB-231 and MDA-MB-231 ${ }^{\text {LG }}$ were embedded in Matrigel membrane and allowed to grow for 6 days. Cells grew in colonies within the matrix and invasive protrusions of cells were indicative of invasive qualities. Two representative fields shown from three independent experiments. Scale bar: $100 \mu \mathrm{m}$. b Matrigel on-top procedure involved culture of cells on matrix overlaid with Matrigel and grown for 6 days. Two representative fields shown from three independ- ent experiments. Scale bar: $100 \mu \mathrm{m}$. c Matrigel invasion chamber assays were performed in duplicate in three independent experiments for both cell lines with $24 \mathrm{~h}$ culture. MDA-MB-231 and MDA-MB$231^{\mathrm{LG}}$ were grown in upper chambers in serum free media corresponding to each cell line. Lower chamber of inserts contained 5\% FBS as a chemoattractant. Cells invading through the matrix and $8 \mu \mathrm{m}$ pore inserts indicated invasion and were stained with crystal violet for visualization. Scale bar: $100 \mu \mathrm{m}$

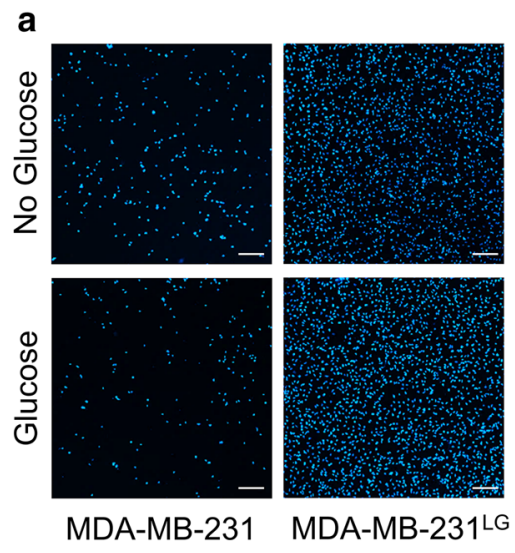

Fig. 7 MDA-MB-231 ${ }^{\mathrm{LG}}$ maintain invasiveness in the presence of glucose. a Matrigel invasion chamber assays were performed in duplicate in three independent experiments in the presence or absence of glucose and invading cells stained with DAPI. Scale bar: $200 \mu \mathrm{m}$. b b

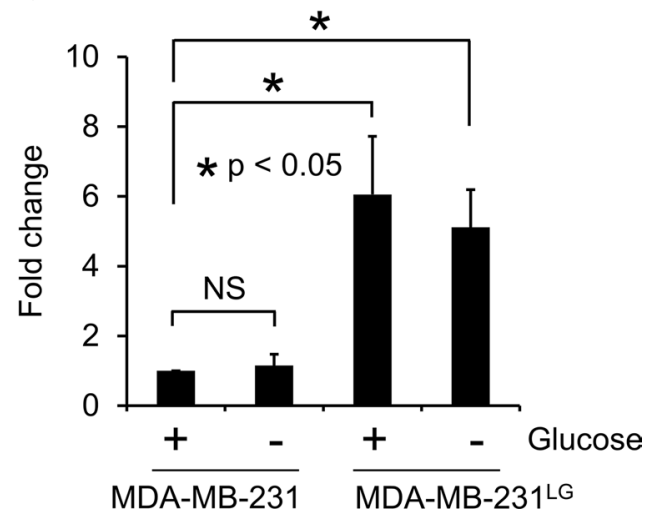

Quantification of results in a. Data represent the mean of three independent experiments normalized to MDA-MB-231+glucose and shown as fold change $\pm \mathrm{SD}$. (* $p<0.05 ; \mathrm{NS}$, not significant) 


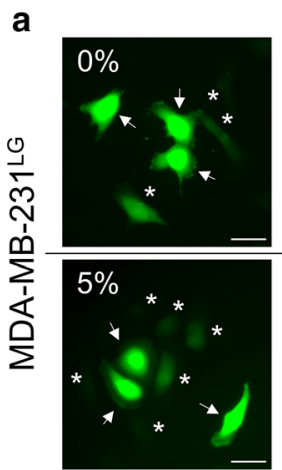

Serum

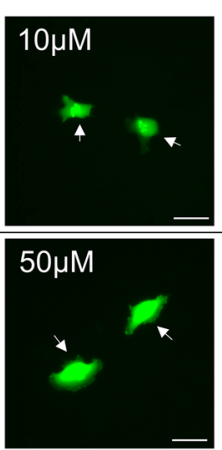

$18 a G A$ b

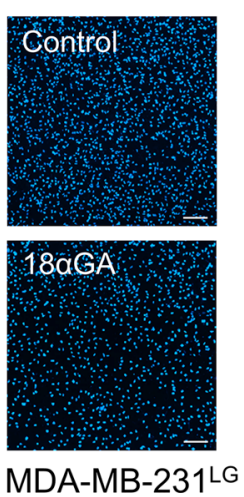

c

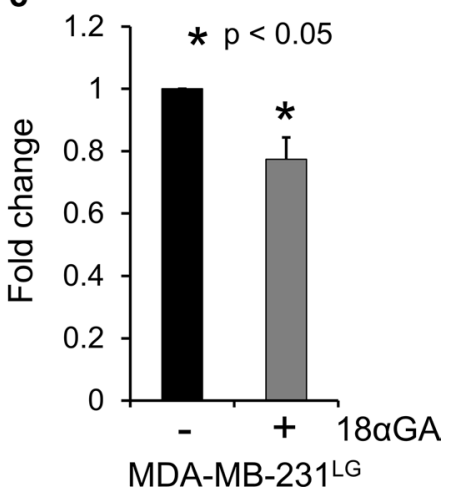

Fig. 8 Inhibition of GJIC reduces invasion in MDA-MB-231 ${ }^{\mathrm{LG}}$. a Calcein dye transfer assays from three independent experiments performed in serum-free or $5 \%$ serum conditions \pm indicated concentrations of $18 \alpha \mathrm{GA}$ for $24 \mathrm{~h}$. Arrows indicate donor cells, asterisks indicate acceptor cells. Scale bar: $50 \mu \mathrm{m}$. b Matrigel invasion chamber assays were performed in duplicate in three independent experiments

et al. 2011; Liu et al. 2015). MDA-MB-231 also fall in the category of "claudin-low" due to their decreased expression of tight junction proteins such as claudin-1 (Majer et al. 2016; Dias et al. 2017; Chiang et al. 2019; Mattern et al. 2019). Collectively, this promotes a decrease in cell-cell attachment and increase in cellular motility. Because the MDA-MB-231 ${ }^{\text {LG }}$ exhibited stronger cell-cell contacts and altered morphology, we explored if these cells underwent a reversal of this process known as mesenchymal-to-epithelial transition (MET) by analysis of cytoskeletal and membrane EMT markers (Chao et al. 2010; Liu et al. 2016). No upregulation of E-cadherin or claudin-1 was observed. Additionally, N-cadherin, a mesenchymal-associated cadherin, was not detected in the MDA-MB-231 (consistent with previous reports (Hazan et al. 1997; Nieman et al. 1999; Wang et al. 2002; Shankar and Nabi 2015) and could not be detected in the MDA-MB-231 ${ }^{\text {LG }}$. However, MDA-MB-231 express cadherin-11 (Nieman et al. 1999; Wang et al. 2002; Li et al. 2011; Satriyo et al. 2019). Cadherin-11, like other cadherins, promotes cell-cell contact through homomeric extracellular interactions that help to link cytoskeletal proteins on the cytoplasmic side. Cadherin-11 is upregulated in invasive breast cancer (Assefnia et al. 2014; Pohlodek et al. 2016). Moreover, inhibition of cadherin-11 in the MDA-MB-231 decreased migration, growth in soft agar, stem cell marker expression, and in vivo tumor growth (Assefnia et al. 2014; Satriyo et al. 2019). The observation of higher cadherin-11 levels in the MDA-MB-231 ${ }^{\mathrm{LG}}$ may contribute to the increase in cell-cell contact in these cells as it exhibited a membrane localized pattern, particularly at sites of cell-cell interaction. Interestingly, we observed a corresponding increase of cadherin-11 at sites of $\beta$-catenin near the plasma membrane. $\beta$-catenin exhibits multiple subcellular localizations with $5 \%$ FBS in the bottom chamber and serum-free media in the top chamber. Invading cells were stained with DAPI. Representative fields shown. Scale bar: $200 \mu \mathrm{m}$. c Quantification of results in b. Data was normalized to MDA-MB-231 $1^{\mathrm{LG}}$ in the absence of $18 \alpha \mathrm{GA}$ and represented as mean $\pm \mathrm{SD}$. $\left({ }^{*} p<0.05\right)$

within the nucleus, cytosol and plasma membrane corresponding to different functions and activity. $\beta$-catenin at the plasma membrane is involved in linking adherens junctions to cytoskeletal proteins such as actin and can contribute to cytoskeletal reorganization dynamics. The markers examined here represent only a small fraction of the many EMT, membrane and cytoskeletal proteins altered in cancer and further characterization is required to confirm a relationship. Nonetheless, these results suggest a potential relationship to the morphologic and membrane changes seen in the MDA-MB- $231^{\mathrm{LG}}$.

Since membrane contact is a fundamental aspect of GJIC, we explored if the plasma membrane interactions observed in the MDA-MB-231 ${ }^{\mathrm{LG}}$ correlated with the formation of gap junctions. $\mathrm{C} \times 43$ is highly expressed in breast tissue and one of the most well studied connexins altered during cancer progression. Similar to previous reports, we observed that parental MDA-MB-231 expressed low levels of $\mathrm{C} \times 43$ with the absence of plasma membrane localization and GJIC in these cells (Qin et al. 2001; 2003, Jiang et al. 2017). Remarkably, C×43 protein was elevated in MDA-MB-231 ${ }^{\mathrm{LG}}$. We observed predominantly lower molecular weight forms of $\mathrm{C} \times 43$ in each cell line similar to previous reports in MDA-MB-231 (Qin et al. 2002; Talhouk et al. 2013; Ming et al. 2015). However, the increase in $\mathrm{C} \times 43$ indicated a potential adaptive response related to glucose levels and $\mathrm{C} \times 43$ expression. Conversely, a recent report demonstrated an inverse relationship between high-glucose levels and $\mathrm{C} \times 43$ expression in osteocyte-like cells (Yang et al. 2020). Augmented connexin protein levels alone are not capable of increasing GJIC when trafficking and membrane transport of connexin proteins remains dysregulated (Qin et al. 2001, 
2003). Thus, we evaluated $\mathrm{C} \times 43$ subcellular localization in MDA-MB-231 ${ }^{\mathrm{LG}}$ cells and found an increase in the presence of this connexin at the membrane, indicative of connexon formation and membrane incorporation. To demonstrate function, we documented the ability of MDA-MB-231 ${ }^{\mathrm{LG}}$ to transfer calcein to neighboring cells and noted an increase in GJIC. An important observation was that not all MDA-MB-231 ${ }^{\mathrm{LG}}$ were coupled via gap junctions, and only a portion of the cells exhibited spread. However, the results described in this report regarding $\mathrm{C} \times 43$ and GJIC are noteworthy because they developed as a consequence of the metabolic response to growth in glucose-limiting conditions without the influence of exogenous connexin expression or the use of pathway inhibitors or activators. Since this is a metabolic circumstance frequently overcome by cancer cells during tumor growth, it provides insight to a potential reprogramming response involving connexins and GJIC that may affect their ability to survive and adapt. Because the connexin family consists of 21 genes, some of which have been shown to be upregulated in different types of cancers and in response to different stimuli, we cannot exclude the influence of other connexins in the MDA-MB-231 ${ }^{\mathrm{LG}}$.

Because cancer cell invasion is a key initial feature of the metastatic process, and because GJIC has been shown to affect this process, we examined if these collective changes affected this aggressive quality. We used Matrigel to evaluate multiple three-dimensional in vitro growth models to characterize cellular invasion. Despite greater membrane contact, increased connexin expression and higher GJIC, all features more similar to normal epithelial cells, the MDA-MB- $231^{\mathrm{LG}}$ demonstrated significantly higher invasive qualities in both the presence and absence of glucose, indicating intrinsic qualities in these cells. Previous studies which directly modulated expression of $\mathrm{C} \times 43$ in the MDA-MB-231 cell line have shown reduction in proliferation, invasive characteristics in three-dimensional culture and an increased state of differentiation in response to $\mathrm{C} \times 43$ expression while an inverse relationship was observed following reduction of C×43 (Qin et al. 2002; Shao et al. 2005; McLachlan et al. 2006; Talhouk et al. 2013). Some of these effects were attributed to gap junction independent functions of $\mathrm{C} \times 43$. Other studies using this cell line have demonstrated both suppression and facilitation of aggressive and metastatic qualities in response to $\mathrm{C} \times 43$ expression ( $\mathrm{Li}$ et al. 2008; Fu et al. 2015; Lin et al. 2016; Kazan et al. 2019). Because this study examined the effects on $\mathrm{C} \times 43$ expression as a result of changes to glucose metabolism, our results are therefore set amongst the background of this metabolic adaptation. Collectively, these studies emphasize the complexities related to the role of $\mathrm{C} \times 43$ in cancer cells that are dependent upon experimental approach and context, highlighting the intricacies related to the study of GJIC and cancer.

To examine if the increase in invasiveness and GJIC in the MDA-MB- $231^{\mathrm{LG}}$ were connected, we evaluated the invasive qualities of these cells during the inhibition of GJIC. We utilized $18 \alpha$-glycerrehetinic acid $(18 \alpha \mathrm{GA})$, a nonselective gap junction inhibitor which uncouples GJIC (Davidson et al. 1986; Salameh and Dhein 2005).The reduced invasive capacity of these cells in the presence of $18 \alpha \mathrm{GA}$ indicated a potential link between these two attributes. The fact that not all MDA-MB-231 ${ }^{\mathrm{LG}}$ exhibited GJIC must be considered when examining the change in invasiveness during $18 \alpha \mathrm{GA}$ treatment. The effects on invasion under these conditions may have been more prominent if the population was more uniformly coupled by GJIC. Thus, careful delineation of these potential relationships will be of importance to our understanding of connexin function in response to metabolic regulation. The results of this study shed light on phenotypic changes that occur in response to nutrient withdrawal and further support a role for cellular metabolism on the regulation of connexins and gap junctional activity in this context.

Supplementary material The online version of this article (https://doi. org/10.1007/s12079-020-00601-3) contains supplementary material, which is available to authorized users.

Acknowledgements We are grateful to the Chicago College of Pharmacy for a Student Research Fellowship to AMM and the Chicago College of Osteopathic Medicine for Kenneth A. Suarez Research Fellowships to PPJ, AEU and CSK. We are indebted to equipment and valuable expertise provided within the Midwestern University Core Facility, Downers Grove, IL.

Open Access This article is licensed under a Creative Commons Attribution 4.0 International License, which permits use, sharing, adaptation, distribution and reproduction in any medium or format, as long as you give appropriate credit to the original author(s) and the source, provide a link to the Creative Commons licence, and indicate if changes were made. The images or other third party material in this article are included in the article's Creative Commons licence, unless indicated otherwise in a credit line to the material. If material is not included in the article's Creative Commons licence and your intended use is not permitted by statutory regulation or exceeds the permitted use, you will need to obtain permission directly from the copyright holder. To view a copy of this licence, visit http://creativecommons.org/licenses/by/4.0/.

\section{References}

Aasen T, Mesnil M, Naus CC et al (2016) Gap junctions and cancer: communicating for 50 years. Nat Rev Cancer 16(12):775-788

Amaro A, Angelini G, Mirisola V et al (2016) A highly invasive subpopulation of MDA-MB-231 breast cancer cells shows accelerated growth, differential chemoresistance, features of apocrine tumors and reduced tumorigenicity in vivo. Oncotarget 7(42):68803-68820 
Assefnia S, Dakshanamurthy S, Guidry Auvil JM et al (2014) Cadherin-11 in poor prognosis malignancies and rheumatoid arthritis: common target, common therapies. Oncotarget 5(6):1458-1474

Bates DC, Sin WC, Aftab Q et al (2007) Connexin43 enhances glioma invasion by a mechanism involving the carboxy terminus. Glia 55(15):1554-1564

Cailleau R, Young R, Olive M et al (1974) Breast tumor cell lines from pleural effusions. J Natl Cancer Inst 53(3):661-674

Chao YL, Shepard CR, Wells A (2010) Breast carcinoma cells reexpress E-cadherin during mesenchymal to epithelial reverting transition. Mol Cancer 9:179

Chen Q, Boire A, Jin X et al (2016) Carcinoma-astrocyte gap junctions promote brain metastasis by cGAMP transfer. Nature 533(7604):493-498

Chiang SK, Chang WC, Chen SE et al (2019) DOCK1 regulates growth and motility through the RRP1B-claudin-1 pathway in claudinlow breast cancer cells. Cancers (Basel) 11(11):1762

Contreras JE, Sanchez HA, Eugenin EA et al (2002) Metabolic inhibition induces opening of unapposed connexin 43 gap junction hemichannels and reduces gap junctional communication in cortical astrocytes in culture. Proc Natl Acad Sci 99(1):495-500

Czyz J, Irmer U, Schulz G et al (2000) Gap-junctional coupling measured by flow cytometry. Exp Cell Res 255(1):40-46

Davidson JS, Baumgarten IM, Harley EH (1986) Reversible inhibition of intercellular junctional communication by glycyrrhetinic acid. Biochem Biophys Res Commun 134(1):29-36

DeBerardinis RJ, Chandel NS (2016) Fundamentals of cancer metabolism. Sci Adv 2(5):e1600200

Dias K, Dvorkin-Gheva A, Hallett RM et al (2017) Claudin-low breast cancer; clinical \& pathological characteristics. PLoS ONE 12(1):e0168669

Dovmark TH, Saccomano M, Hulikova A et al (2017) Connexin-43 channels are a pathway for discharging lactate from glycolytic pancreatic ductal adenocarcinoma cells. Oncogene 36(32):4538-4550

Dovmark TH, Hulikova A, Niederer SA et al (2018) Normoxic cells remotely regulate the acid-base balance of cells at the hypoxic core of connexin-coupled tumor growths. FASEB J 32(1):83-96

el-Sabban ME, Pauli BU (1994) Adhesion-mediated gap junctional communication between lung-metastatatic cancer cells and endothelium. Invasion Metastasis 14(1-6):164-176

Fu Y, Shao ZM, He QZ et al (2015) Hsa-miR-206 represses the proliferation and invasion of breast cancer cells by targeting $\mathrm{C} \times 43$. Eur Rev Med Pharmacol Sci 19(11):2091-2104

Garcia-Jimenez C, Goding CR (2019) Starvation and pseudo-starvation as drivers of cancer metastasis through translation reprogramming. Cell Metab 29(2):254-267

Ghosh S, Kumar A, Tripathi RP et al (2014) Connexin-43 regulates p38-mediated cell migration and invasion induced selectively in tumour cells by low doses of gamma-radiation in an ERK1/2-independent manner. Carcinogenesis 35(2):383-395

Gillies RJ, Schornack PA, Secomb TW et al (1999) Causes and effects of heterogeneous perfusion in tumors. Neoplasia 1(3):197-207

Goldberg GS, Bechberger JF, Naus CC (1995) A pre-loading method of evaluating gap junctional communication by fluorescent dye transfer. Biotechniques 18(3):490-497

Hazan RB, Kang L, Whooley BP et al (1997) N-cadherin promotes adhesion between invasive breast cancer cells and the stroma. Cell Adhes Commun 4(6):399-411

Hollestelle A, Nagel JH, Smid M et al (2010) Distinct gene mutation profiles among luminal-type and basal-type breast cancer cell lines. Breast Cancer Res Treat 121(1):53-64

Hong X, Sin WC, Harris AL et al (2015) Gap junctions modulate glioma invasion by direct transfer of microRNA. Oncotarget 6(17):15566-15577
Jiang G, Dong S, Yu M et al (2017) Influence of gap junction intercellular communication composed of connexin 43 on the antineoplastic effect of adriamycin in breast cancer cells. Oncol Lett 13(2):857-866

Kazan JM, El-Saghir J, Saliba J et al (2019) C×43 expression correlates with breast cancer metastasis in MDA-MB-231 cells in vitro, in a mouse xenograft model and in human breast cancer tissues. Cancers (Basel) 11(4):460

King TJ, Lampe PD (2004) The gap junction protein connexin32 is a mouse lung tumor suppressor. Cancer Res 64(20):7191-7196

Lamiche C, Clarhaut J, Strale PO et al (2012) The gap junction protein $\mathrm{C} \times 43$ is involved in the bone-targeted metastatic behaviour of human prostate cancer cells. Clin Exp Metastasis 29(2):111-122

Li Z, Zhou Z, Donahue HJ (2008) Alterations in CX43 and OBcadherin affect breast cancer cell metastatic potential. Clin Exp Metastasis 25(3):265-272

Li Y, Guo Z, Chen H et al (2011) HOXC8-dependent cadherin 11 expression facilitates breast cancer cell migration through trio and rac. Genes Cancer 2(9):880-888

Lin ZJ, Ming J, Yang L et al (2016) Mechanism of regulatory effect of MicroRNA-206 on Connexin 43 in distant metastasis of breast cancer. Chin Med J (Engl) 129(4):424-434

Liu CY, Lin HH, Tang MJ et al (2015) Vimentin contributes to epithelial-mesenchymal transition cancer cell mechanics by mediating cytoskeletal organization and focal adhesion maturation. Oncotarget 6(18):15966-15983

Liu F, Gu LN, Shan BE et al (2016) Biomarkers for EMT and MET in breast cancer: an update. Oncol Lett 12(6):4869-4876

Louie E, Nik S, Chen JS et al (2010) Identification of a stem-like cell population by exposing metastatic breast cancer cell lines to repetitive cycles of hypoxia and reoxygenation. Breast Cancer Res 12(6):R94

Majer A, Blanchard AA, Medina S et al (2016) Claudin 1 expression levels affect miRNA dynamics in human basal-like breast cancer cells. DNA Cell Biol 35(7):328-339

Mattern J, Roghi CS, Hurtz M et al (2019) ADAM15 mediates upregulation of Claudin-1 expression in breast cancer cells. Sci Rep 9(1): 12540

McLachlan E, Shao Q, Wang HL et al (2006) Connexins act as tumor suppressors in three-dimensional mammary cell organoids by regulating differentiation and angiogenesis. Cancer Res 66(20):9886-9894

Mehta PP, Hotz-Wagenblatt A, Rose B et al (1991) Incorporation of the gene for a cell-cell channel protein into transformed cells leads to normalization of growth. J Membr Biol 124(3):207-225

Ming J, Zhou Y, Du J et al (2015) miR-381 suppresses C/EBPalphadependent $\mathrm{C} \times 43$ expression in breast cancer cells. Biosci Rep 35(6): $\mathrm{e} 00266$

Morata-Tarifa C, Jimenez G, Garcia MA et al (2016) Low adherent cancer cell subpopulations are enriched in tumorigenic and metastatic epithelial-to-mesenchymal transition-induced cancer stem-like cells. Sci Rep 6:18772

Nielsen MS, Axelsen LN, Sorgen PL et al (2012) Gap junctions. Compr Physiol 2(3):1981-2035

Nieman MT, Prudoff RS, Johnson KR et al (1999) N-cadherin promotes motility in human breast cancer cells regardless of their E-cadherin expression. J Cell Biol 147(3):631-644

Ogawa K, Pitchakarn P, Suzuki S et al (2012) Silencing of connexin 43 suppresses invasion, migration and lung metastasis of rat hepatocellular carcinoma cells. Cancer Sci 103(5):860-867

Pavlova NN, Thompson CB (2016) The emerging hallmarks of cancer metabolism. Cell Metab 23(1):27-47

Pishvaian MJ, Feltes CM, Thompson P et al (1999) Cadherin-11 is expressed in invasive breast cancer cell lines. Cancer Res 59(4):947-952 
Pohlodek K, Tan YY, Singer CF et al (2016) Cadherin-11 expression is upregulated in invasive human breast cancer. Oncol Lett 12(6):4393-4398

Qin H, Shao Q, Belliveau DJ et al (2001) Aggregated DsRed-tagged $\mathrm{C} \times 43$ and over-expressed $\mathrm{C} \times 43$ are targeted to lysosomes in human breast cancer cells. Cell Commun Adhes 8(4-6):433-439

Qin H, Shao Q, Curtis H et al (2002) Retroviral delivery of connexin genes to human breast tumor cells inhibits in vivo tumor growth by a mechanism that is independent of significant gap junctional intercellular communication. J Biol Chem 277(32):29132-29138

Qin H, Shao Q, Igdoura SA et al (2003) Lysosomal and proteasomal degradation play distinct roles in the life cycle of $\mathrm{C} \times 43$ in gap junctional intercellular communication-deficient and -competent breast tumor cells. J Biol Chem 278(32):30005-30014

Salameh A, Dhein S (2005) Pharmacology of gap junctions. New pharmacological targets for treatment of arrhythmia, seizure and cancer? Biochim Biophys Acta 1719(1-2):36-58

Satriyo PB, Bamodu OA, Chen JH et al (2019) Cadherin 11 inhibition downregulates beta-catenin, deactivates the canonical WNT signalling pathway and suppresses the cancer stem cell-like phenotype of triple negative breast cancer. J Clin Med 8(2):148

Shankar J, Nabi IR (2015) Actin cytoskeleton regulation of epithelial mesenchymal transition in metastatic cancer cells. PLoS ONE 10(3): 0119954

Shao Q, Wang H, McLachlan E et al (2005) Down-regulation of $\mathrm{C} \times 43$ by retroviral delivery of small interfering RNA promotes an aggressive breast cancer cell phenotype. Cancer Res 65(7):2705-2711

Simoes RV, Serganova IS, Kruchevsky N et al (2015) Metabolic plasticity of metastatic breast cancer cells: adaptation to changes in the microenvironment. Neoplasia 17(8):671-684

Talhouk RS, Fares MB, Rahme GJ et al (2013) Context dependent reversion of tumor phenotype by connexin-43 expression in
MDA-MB231 cells and MCF-7 cells: role of beta-catenin/connexin43 association. Exp Cell Res 319(20):3065-3080

Tang B, Peng ZH, Yu PW et al (2013) Aberrant expression of C $\times 43$ is associated with the peritoneal metastasis of gastric cancer and $\mathrm{C} \times 43$-mediated gap junction enhances gastric cancer cell diapedesis from peritoneal mesothelium. PLoS ONE 8(9):e74527

Vaupel P, Kallinowski F, Okunieff P (1989) Blood flow, oxygen and nutrient supply, and metabolic microenvironment of human tumors: a review. Cancer Res 49(23):6449-6465

Wang F, Hansen RK, Radisky D et al (2002) Phenotypic reversion or death of cancer cells by altering signaling pathways in threedimensional contexts. J Natl Cancer Inst 94(19):1494-1503

Wang WK, Chen MC, Leong HF et al (2014) Connexin 43 suppresses tumor angiogenesis by down-regulation of vascular endothelial growth factor via hypoxic-induced factor-1alpha. Int J Mol Sci 16(1):439-451

Wang X, Liu Y, Zhou K et al (2015) Isolation and characterization of CD105+/CD90 + subpopulation in breast cancer MDA-MB-231 cell line. Int J Clin Exp Pathol 8(5):5105-5112

Yang L, Zhou G, Li M et al (2020) High glucose downregulates Connexin 43 expression and its gap junction and hemichannel function in osteocyte-like MLO-Y4 cells through activation of the p38MAPK/ERK signal pathway. Diabetes Metab Syndr Obes 13:545-557

Zibara K, Awada Z, Dib L et al (2015) Anti-angiogenesis therapy and gap junction inhibition reduce MDA-MB-231 breast cancer cell invasion and metastasis in vitro and in vivo. Sci Rep 5:12598

Publisher's Note Springer Nature remains neutral with regard to jurisdictional claims in published maps and institutional affiliations. 